\title{
An NFC E-Learning Platform for Interactive and Ubiquitous Learning
}

\author{
Wei Hsun Lee \\ Department of Transportation \& Communication \\ Management Science \\ National Cheng Kung University \\ Tainan, Taiwan \\ leews@mail.ncku.edu.tw
}

\author{
Ming Chieh Kuo \\ Department of Transportation \& Communication \\ Management Science \\ National Cheng Kung University \\ Tainan, Taiwan \\ R96014050@mail.ncku.edu.tw
}

\begin{abstract}
In recent years, the digital learning technology has evolved from E-Learning to M-Learning and U-Learning. However, most of these digital learning paradigms do not support the interactive teaching activities in class. With NFC (near field communication) technology, the interactions between teachers and students can be largely enhanced. In this work, an NFC Ulearning platform is proposed with four innovative interactive teaching scenarios as well as several NFC learning interactive functions. Compared to traditional M-Learning or U-Learning models, the proposed NFC U-Learning model can enhance the interactive teaching activities in class.
\end{abstract}

Keywords- NFC; interactive; ubiquitous learning; e-Learning platform

\section{INTRODUCTION}

In the past decade, the development of information technologies such as wireless networks, sensor technology, and mobile technology have changed the teaching and learning patterns. The evolution of E-Learning paradigm shift diagram is shown in Figure.1. Most traditional learning methods are face-to-face teaching styles which are mostly spoon-feeding, mechanical teaching modes, it is generally considered inefficient and spatiotemporal limited in traditional teaching and learning styles.

E-learning releases the spatiotemporal constraint which is suitable for distant learning, and learners can study whenever they have access to Internet. E-learning is the delivery of teaching materials via electronic media, such as the Internet, intranets, extranets, satellite broadcast, audio/video tape, interactive TV and CD-ROM[1]. Nevertheless, there are some disadvantages in traditional E-Learning method. For instance, E-learning decreases the relationships between the teachers with students as well as the students with other students. Students and teachers must know how to use computers for Elearning, and computers must be available[1]. Mobile learning (M-learning) is the idea that a student can learn from any place at any time using portable learning devices[2], such as tablets or smart phones. However, it does not take the context information from surrounding learning environment into account so that it is classified as a passive learning pattern, as the E-Learning does. U-learning method is classified as an active learning pattern comparing to M-Learning, it allows learners to obtain learning information from the learning environment through variety type of sensors[3]. Ubiquitous computing is the highest level of interaction between humans and computers [4]. By considering the spatiotemporal environment of the students, U-Learning is most suitable for self-learning outside the class because it has the advantages of permanent, availability, timeliness, interactive, adaptive[5]. However, many interactions among the teachers and students in the class lack of the technology support, such as dynamic grouping, step by step interactive examination and discussion, etc. These class teaching and learning activities can be assisted by the NFC and wireless communication technology, so that the teaching activities in class such as dynamic grouping can be done quickly and conveniently.

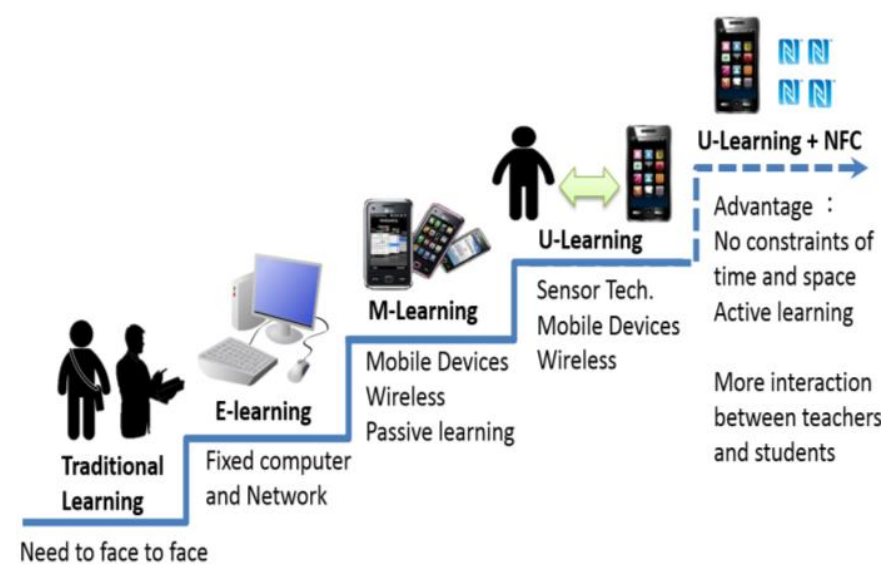

FIGURE I. THE COMPONENTS OF PARADIGM SHIFTS IN ELEARNING

In this paper, an NFC U-Learning platform for interactive and ubiquitous learning is proposed, which has the potential for enhancing the learning and teaching activities because it is simple, easy to use, accessible and invisible to technology. Students or teachers do not need the technical expertise and neither for longtime training. Four innovative teaching applications including dynamic grouping, creative scenariobased learning, interactive examination, and gradual learning are designed and implemented in this platform, as shown in Figure 2. Teachers can design their teaching scenarios by designing and customizing the NFC tags with customized content or built-in connection URL to web digital contents. With the development of NFC technology, the effectiveness of 
U-learning can be further extended, especially in applying it in the interactive activities in the class. For the interactive examination as the example, teacher can quiz one question and collect the answers from students immediately by gathering the NFC touching answer tags activity and then the teachers can understand students' thinking and discuss the question according to their answers. After one question is done, then continues the follows. By this way, it can improve interactivity and enhance learning efficiency compared to traditional batchbased examination.

This rest of this paper is structured as follows. The related work about U-Learning and interactive learning are discussed in Section II. Section III discusses the design and implementation of system prototype and NFC U-Learning Modules. The use cases, system operation and design details of the four innovative applications with sequence diagrams are presented in Section IV. Conclusions and future works are discussed in Section V.

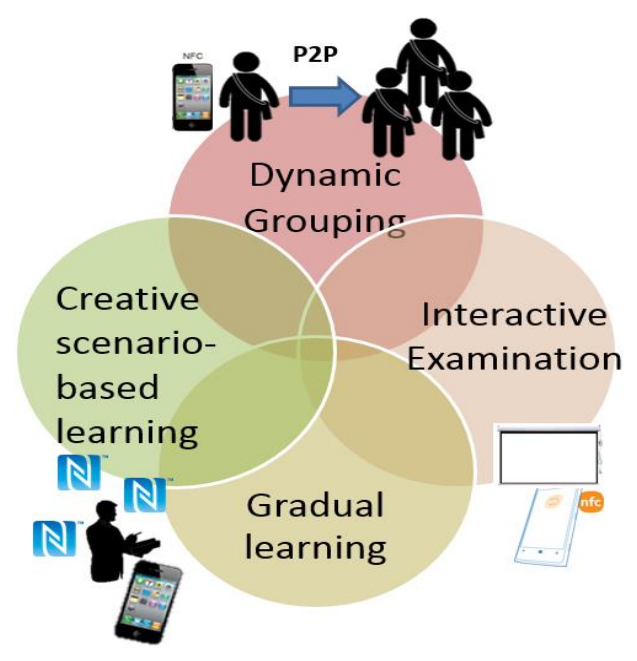

FIGURE II. FOURINNOVATIVEAPPLICATIONS OF NFC U-LEARNING PLATFORM

\section{RELATED WORK}

In literature, interaction techniques including touch, gesture recognition, natural voice-based output. Review of interactive learning in U-learning and NFC technology that use of tangibles user interface (TUI) learning context. When users using NFC device to interacting with objects, ITU can made to reduce the time to learn systems. Borrego [6] proposed a pervasive system which provides students the access to bibliographic sources. The application area is university libraries and students "touches" a bibliographic source can receives personalized information on NFC device. This studies used questionnaires to evaluate user acceptance. However, the interaction between teachers and students is one-way communication, and only fifteen students participated in the experiment ( 5 female and 10 male).

Ivanov [7] presents the design, development and implementation of the pervasive learning system for children, system let children can use the service to scan surrounding augmented objects and verbalize their identity and characteristics. Interaction between children and objects from learning environment should be simple and intuitive[7]. Nevertheless, the learning scenarios are only for the children, NFC U-Learning platform learning environment can apply to learner of all ages. Iván Sánchez [3] presentation of NFC as an enable technology to create easy-to-use interactive learning environments for children and developed to support children in learning to read, in learning a foreign language, and in studying biology. One application developed to persuade children to run outdoors[3]. But, the system designed labels are fixed, the different scenarios cannot dynamically adjust the content.

\section{NFC UBIQUITOUS LEARNING PLATFORM}

The idea of the proposed NFC U-learning Platform is to apply NFC reader mode, $\mathrm{P} 2 \mathrm{P}$ mode and wireless communications (Wi-Fi, Bluetooth) technologies to design a few innovative interactive teaching and learning functions for ubiquitous learning. The platform is consisted by four parts including identification, equipment, function, and application as shown in Figure 3. The roles or objects are identified by NFC tags or NFC phones (with secure element), and the identifications are happened when one equipment is touched by another one. Several basic functions are designed and implemented, such as read/write tags, P2P data exchange, touch and download, etc. Teachers can design their own teaching applications by combining several provided functions in the platform. Six types of teaching interaction applications in class can be customized by the teacher, as illustrated in Figure 3. For example, a "creative scenario-based learning" scenario may be consisted of some predefined tags with "Touch and Down" or "Touch and Send" function that students can accomplish the assigned task by touching the tags under the scenario instructions. The "interactive examination" can be done by interactions between teacher and students. Teachers show up one multiple choice question on the screen, students touch one of the answer tags (Tag A/B/C/D) by NFC phone and send the result to the teacher's notebook by Bluetooth, then the collected answers from students can be immediately show up on the screen. In this way, teacher can realize the student understandings in the direct and immediate way, he/she can decide to make more discussion about the question or continue on next question one by one.

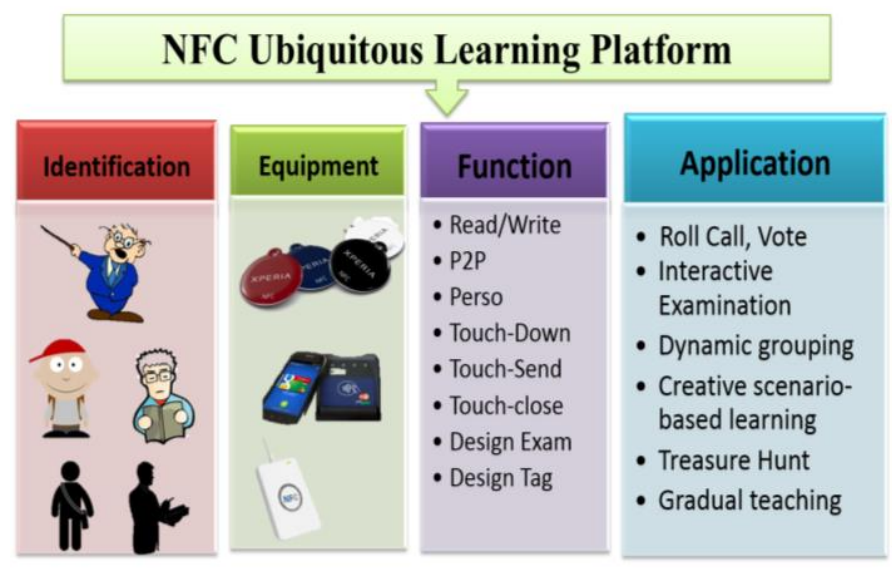

FIGURE III. 
Several modules are designed to support the proposed NFC ubiquitous learning platform including NFC module, P2P module, UI module, file management module, Bluetooth connection module, read tag module, answer connection module, question modules and tag design modules. Those modules described as Table 1:

TABLE I. The Modules OF THE NFC UbiQuitous LEARNING PlATFORM

\begin{tabular}{|l|l|}
\hline \multicolumn{1}{|c|}{ Module } & \multicolumn{1}{c|}{ Content } \\
\hline $\begin{array}{l}\text { NFC reader } \\
\text { module }\end{array}$ & $\begin{array}{l}\text { Read the data from the the NDEF[8]format } \\
\text { NFC tag or smart cards via JSR257 interface }\end{array}$ \\
\hline P2P module & $\begin{array}{l}\text { Exchange information between two NFC } \\
\text { phones in P2P mode. }\end{array}$ \\
\hline UI module & $\begin{array}{l}\text { UI module is responsible for all the interactions } \\
\text { to users through Android App. }\end{array}$ \\
\hline $\begin{array}{l}\text { File } \\
\text { management } \\
\text { module }\end{array}$ & $\begin{array}{l}\text { File management module is responsible for } \\
\text { accessing the phone's memory storage. }\end{array}$ \\
\hline $\begin{array}{l}\text { Bluetooth } \\
\text { connection } \\
\text { module }\end{array}$ & $\begin{array}{l}\text { It construct a TCP communication channel } \\
\text { between smartphone and computer. }\end{array}$ \\
\hline $\begin{array}{l}\text { Answer } \\
\text { connection } \\
\text { module }\end{array}$ & $\begin{array}{l}\text { Get the Tag ID through readerand record the } \\
\text { selection of students' answers. }\end{array}$ \\
\hline $\begin{array}{l}\text { Tag design } \\
\text { module }\end{array}$ & $\begin{array}{l}\text { Teacher can create customized tagsby this } \\
\text { module by writing the tag type, tag content, } \\
\text { URL in NDEF[8] format. }\end{array}$ \\
\hline
\end{tabular}

\section{APPLICATION SCENARIOS}

The innovative interactive teaching and learning applications proposed in this work are detail discussed with use cases, system operations and sequence diagrams as the following sub-sections.

\section{A. Use Cases and System Operations}

The main roles in the proposed model are students and teachers. In this study, four innovative interactive U-Learning scenarios are designed and implemented including dynamic grouping, creative scenario-based learning, interactive examination, and gradual learning, the system use cases are shown in Figure 4.

Several scenarios of the teacher and student interactions in class of the proposed NFC ubiquitous learning platform are illustrated as below and shown in Figure 5.

a. Student enrolls a course by registering the IC serial number of the secure element via using NFC phone to touch the reader. (flow 1 )

b. When attending class, students use NFC phone to roll call by touching the reader of the teacher's notebook.

c. The teacher's notebook can collect information by Bluetooth and display the results on the screen, such as grouping result or question answers. The collected result can be stored in the database for future use.

d. Students use NFC P2P mode for dynamic grouping. After grouping, group cooperative learning or group discussion can be proceeded. (flow 2) e. Teachers can design their own tag for a customized teaching scenario, such as gradual learning.

f. Students use NFC phone (reader mode) to touch the tags at different locations to activate different actions such as "touch and send" or "touch and download" for completing the teacher's assign tasks. (flow 5)

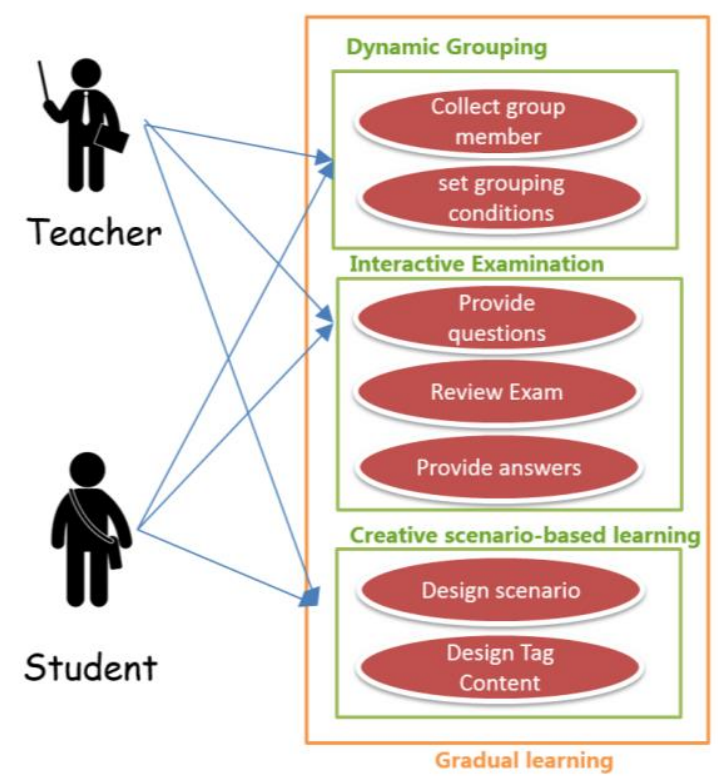

FIGURE IV

USE CASES

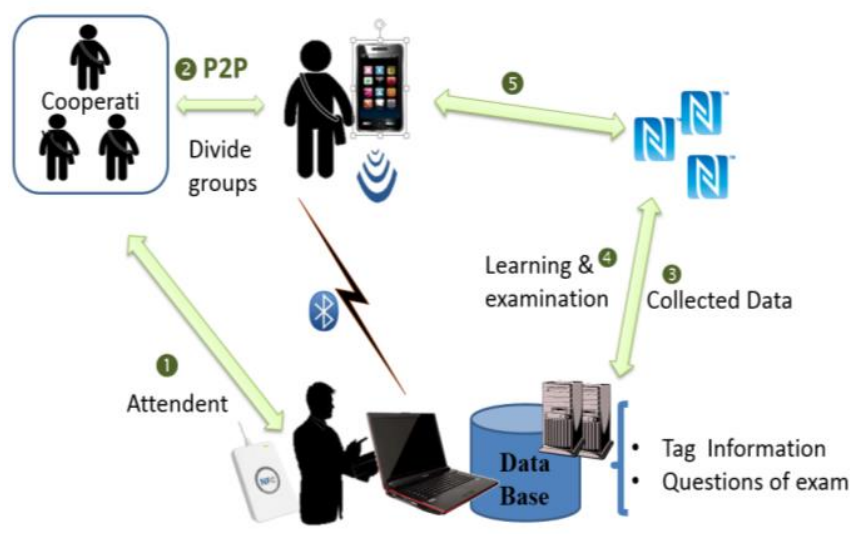

FIGURE V. SYSTEM OPERATIONS EXAMPLE OF NFC UBIQUITOUS LEARNING

\section{B. Dynamic Grouping}

NFC P2P mode is applied to achieving fast dynamic grouping in class. Teacher sets grouping conditions (e.g., number of Students) and activating grouping task. Students use NFC P2P mode to connect with group leader, and group leader collects the serial number of group member by NFC P2P mode, and then the leader and the teacher's notebook establish a Bluetooth connection to forward the grouping result to teacher's notebook by Bluetooth. The sequence diagram of dynamic grouping is shown in Figure 6. 


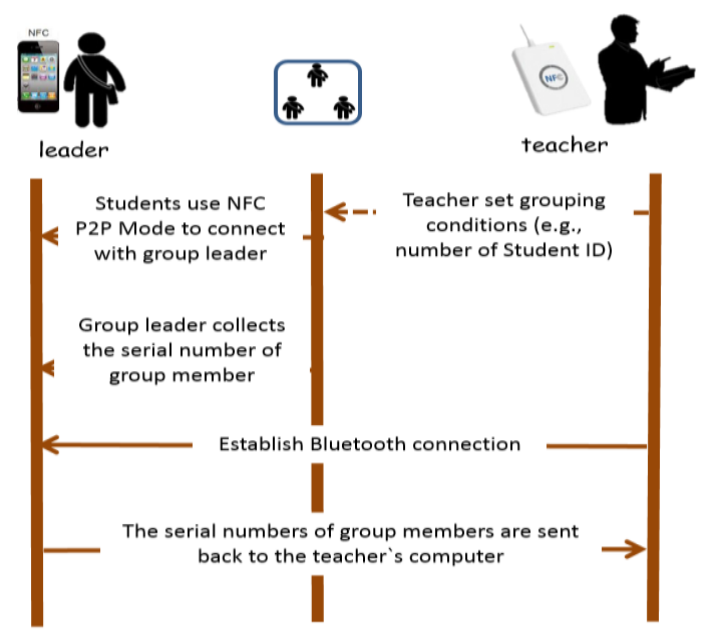

FIGURE VI.

SEQUENCE DIAGRAM OF DYNAMIC GROUPING

\section{Interactive Examination}

At first, teacher should prepare the questions of the examination. When interactive examination start, and the first question is displayed on the IWB (Interactive whiteboard), students use NFC phone to touch the answer tags (A/B/C/D) to submit their answers. The computer collects the answers in real-time display on the IWB. Teachers and students interactively review and discuss the questions and answers, the sequence diagram is shown in Figure 7.

By this way, teacher can understand students' thinking through students' answers with names, then the interactivity and learning effect can be enhanced.

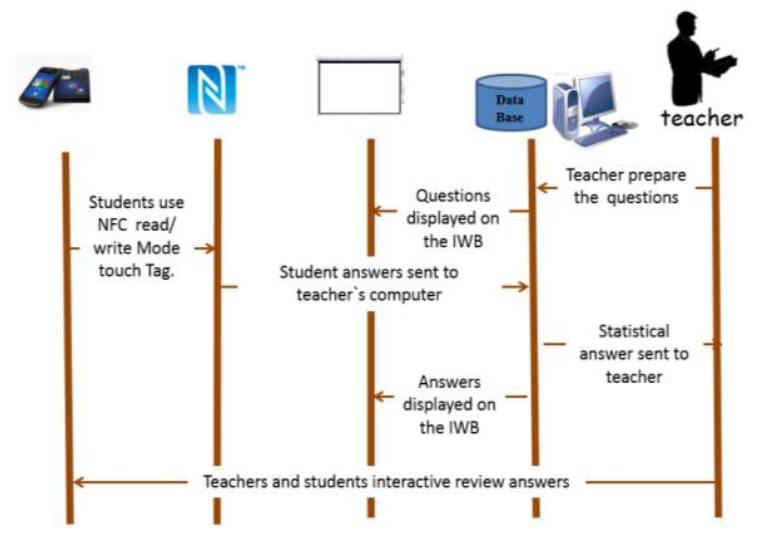

FIGURE VII. SEQUENCE DIAGRAM OF INTERACTIVE EXAMINATION

\section{Creative Scenario-Based Learning}

Teachers design their own teaching materials by assigning the actions, contents, and connection URL to the NFC tags, and put on these tags to the designated location in the pre-designed teaching scenario. Teacher assigns a task for students, and students touch the tags to complete the assignment. All the interactions are recorded in the database to recognize the learning effect of each student. The sequence diagram of dynamic grouping is shown in Figure 8.

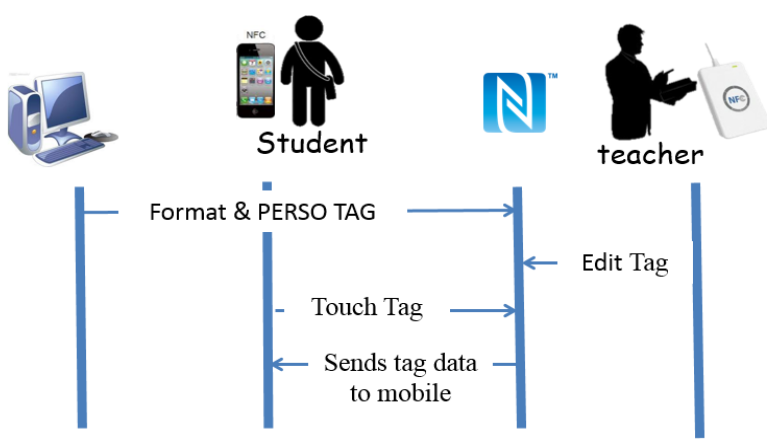

FIGURE VIII.

SEQUENCE DIAGRAM OF CREATIVE SCENARIOBASED LEARNING

\section{CONCLUSIONS AND FUTURE WORK}

In this work, an NFC U-learning platform with four innovative interactive teaching scenarios as well as several NFC learning interactive functions is proposed. Compared to traditional M-Learning or U-Learning models, the proposed NFC U-Learning model can largely enhance the interactive teaching activities which are not supported in most previous models. Teachers can design their own teaching materials with dynamic relationship connected to NFC tags by writing connection URL on them. Through NFC phones and interactive whiteboard, teachers can carry out interactive examinations more conveniently and can immediately review examinations as well. Student uses NFC phones to touch tags with gradual difficulty levels and obtains the spatiotemporal and personal sensitive learning contents. Therefore, they can achieve the effects of gradual learning. It is important to understand whether this platform is able to meet the requirements in teaching and learning. In the future, this platform is expected to be exercised in the real teaching course, and two questionnaires for teachers and students will be designed and investigated.

\section{REFERENCES}

[1] N. C. Ozuorcun and F. Tabak, "Is M-learning Versus E-learning or are They Supporting Each Other?," Procedia - Social and Behavioral Sciences, vol. 46, pp. 299-305, 2012.

[2] S. Kumar, "M-LEARNING: A NEW LEARNING PARADIGM " International Journal on New Trends in Education and Their Implications, vol. 4, pp. 24-34, April 2013.

[3] I. Sánchez, M. Cortés, J. Riekki, and M. Oja, "NFC-based interactive learning environments for children," presented at the Proceedings of the 10th International Conference on Interaction Design and Children, Ann Arbor, Michigan, 2011.

[4] Vedat Coskun, Kerem Ok, Busra Ozdenizci, Near Field Communication (NFC): From Theory to Practice: Wiley, 2011.

[5] G.-J. Hwang, H.-C. Chu, Y.-S. Lin, and C.-C. Tsai, "A knowledge acquisition approach to developing Mindtools for organizing and sharing differentiating knowledge in a ubiquitous learning environment," Comput. Educ., vol. 57, pp. 1368-1377, 2011.

[6] F. Borrego-Jaraba, G. C. García, I. L. Ruiz, and M. Á. Gómez-Nieto, "An NFC based context-aware solution for access to bibliographic sources in university environments," Journal of Ambient Intelligence and Smart Environments, vol. 5, pp. 105-118, 01/01/ 2013.

[7] R. Ivanov, "NFC-based Pervasive Learning Service for Children," International Conference on Computer Systems and Technologies, June $28-292013$.

[8] NFC. Forum, "NFC Data Exchange Format," July 242006. 